\title{
O USO DAS FERRAMENTAS CONTÁBEIS COMO APOIO GERENCIAL PARA O PEQUENO PRODUTOR RURAL
}

\section{ARTIGO ORIGINAL}

GOMES, Jadson Rodrigues ${ }^{1}$, SANTOS, Adélia Teles dos², COSTA, Silvânia Gouveia Alves $^{3}$

GOMES, Jadson Rodrigues. SANTOS, Adélia Teles dos. COSTA, Silvânia Gouveia Alves. $\mathbf{O}$ uso das ferramentas contábeis como apoio gerencial para o pequeno produtor rural. Revista Científica Multidisciplinar Núcleo do Conhecimento. Ano 06, Ed. 04, Vol. 04, pp. 170-183. Abril de 2021. ISSN: 2448-0959, Link de acesso: https://www.nucleodoconhecimento.com.br/contabilidade/contabeis-como-apoio

\section{RESUMO}

O presente estudo traz uma abordagem clara e objetiva do tema "o uso das ferramentas contábeis como apoio gerencial para o pequeno produtor rural". Tem como principal objetivo apontar a importância da contabilidade nos empreendimentos rurais e conscientizar os pequenos produtores para o grave erro de negligenciar a contabilidade. Desse modo, é apresentado os conceitos de contabilidade rural e suas características, destacando a importância da contabilidade para as empresas rurais e o produtor rural. E as principais ferramentas gerenciais, como o inventario, o livro caixa, o fluxo de caixa e a demonstração do resultado do exercício (DRE), bem como, sua utilização e finalidade. Ao final deste estudo através de uma metodologia de

\footnotetext{
${ }^{1}$ Especialização em Contabilidade Pública e LRF -Universidade Cândido Mendes - UCAM. /Bacharel em Ciências Contábeis-Universidade Norte do Paraná -UNOPAR./ Técnico em Agronegócio - Serviço Nacional de Aprendizagem Rural -SENAR-Rede e-Tec-Brasil

2 Tecnólogo em Recursos Humanos- Universidade Norte do Paraná -UNOPAR. Tecnólogo em LogísticaUniversidade Norte do Paraná - UNOPAR. Técnico em Agronegócio- Serviço Nacional de Aprendizagem Rural SENAR- Rede e-Tec-Brasil.

${ }^{3}$ Orientadora. MBA em Finanças e Controladoria pela FGV, MBA em Gestão e Desenvolvimento de Pessoas pela UNIME, Graduada em Administração.
}

RC: 82128

Disponível em: 
pesquisa bibliográfica e comportamental, concluiu-se que o pequeno produtor rural precisa superar o desafio de romper com velhos hábitos

prejudiciais e, começar olhar o seu empreendimento como uma empresa de forma organizada.

Palavras-chave: Contabilidade Rural, Ferramentas Gerenciai, Produtor Rural.

\section{INTRODUÇÃO}

Tendo em vista a falta de técnicas gerencias dos pequenos produtores rurais em fazer o registro de informações importantes e obrigatórias da contabilidade, pretende-se apontar esse desafio para a evolução do agronegócio brasileiro. A falta de uso de tais instrumentos impacta negativamente nos resultados dos empreendimentos e, consequentemente, na economia nacional uma vez que o agronegócio representa um papel fundamental para a economia do Brasil, e é responsável por pelo menos 1/3 do Produto Interno Bruto - PIB. Desse modo, o pequeno produtor rural tem sua parcela de responsabilidade e contribuição para o desenvolvimento do agronegócio.

O presente estudo tem como objetivo enfatizar a importância da contabilidade para o pequeno produtor rural, bem como apresentar os benefícios que as ferramentas gerenciais pode proporcionar para o seu negócio e, demonstrar os métodos práticos de utilização da ciência contábil como instrumento de gestão no desenvolvimento das suas atividades.

Diante do exposto, foi desenvolvido uma pesquisa bibliográfica e comportamental tendo como resultado a necessidade de superar esse desafio por parte dos pequenos produtores. Sendo assim, a finalidade deste trabalho é conscientizar o

pequeno agricultor para a necessidade de romper com velhos hábitos prejudiciais e conhecer a contabilidade e suas ferramentas. 
Assim, o trabalho apresenta os conceitos de contabilidade rural e suas características, a importância da contabilidade nos empreendimentos e suas ferramentas básicas gerenciais. Para isso, é apresentado o inventario, o livro caixa, o fluxo de caixa e a DRE com seus conceitos, utilização e finalidade para uma melhor compreensão do assunto abordado.

Trata-se de uma pesquisa de extrema importância para o meio rural e todos os envolvidos no agronegócio, sobretudo o pequeno produtor pessoa física e os agricultores familiares, levando em conta a sua relevância e colaboração para a evolução da economia nacional.

\section{A CONTABILIDADE RURAL E SUAS CARACTERÍSTICAS}

\subsection{CONCEITUAÇÃO}

A contabilidade é a ciência que estuda e controla o patrimônio das entidades. E, a contabilidade rural é uma especialização da contabilidade geral aplicada às empresas rurais. (MARION, 2014, p.3).São ramos da ciência contábil; a contabilidade zootécnica, a contabilidade pecuária, a contabilidade agropecuária e a contabilidade agroindustrial.

Desse modo, se tratando de contabilidade rural, os ativos são classificados como ativos biológicos e produção agrícola. O CPC29 define ativos biológicos os seres vivos, animais e plantas. E produção agrícola, o produto resultante do ativo biológico em plena colheita. O patrimônio rural é constituído de:

- Ativos: caixas, animais, terra, tratores, fertilizantes, sementes, defensivos agrícolas.

- Passivos: empréstimos bancários, dívidas trabalhistas, entre outros.

- Patrimônio líquido: as reservas de capital.

De uma forma simplificada, a contabilidade possui em sua estrutura 5 itens básicos para sua elaboração; no Balanço Patrimonial; bens, direitos, obrigações, na DRE;

RC: 82128

Disponível em:

https://www.nucleodoconhecimento.com.br/contabilidade/contabeiscomo-apoio 
receitas e despesas. A contabilidade se faz necessária e importante dentro das propriedades rurais, pois, é um instrumento de desenvolvimento do negócio.

Para Horngrenetal (2002, p.5) a contabilidade é:

O sistema de informação que mede as atividades do negócio, processa as informações em relatórios e comunica os resultados para os tomadores de decisão. É frequentemente chamada de "a linguagem dos negócios". Quanto melhor você entender essa linguagem, melhores serão suas decisões de negócio.

Portanto, com tantas ramificações, a contabilidade vem se especializar para melhor organizar o patrimônio dos diversos empreendimentos. Entretanto, entender a contabilidade e sua linguagem dentro das cadeias do agronegócio é desenvolver o potencial econômico das empresas nesse segmento.

O objetivo da contabilidade no agronegócio é calcular e informar claramente as alterações que podem afetar o patrimônio das empresas rurais. É através das demonstrações contábeis, elaboradas a partir de registros obtidos no dia a dia que é possível analisar a evolução da empresa. De modo, a manter o empreendimento em dia com as suas obrigações e assim contribuir para o crescimento do negócio.

Carneiro e Carneiro (1933, p.46) afirma que: "Em Contabilidade os fatos administrativos consequentes do trabalho merecem registro e cuidado. Para a apuração do custo da produção temos necessidade de contabilizar a expressão econômica do trabalho empregado".

A contabilidade é uma importante ferramenta administrativa para o controle do patrimônio. Patrimônio é o conjunto de bens direitos e obrigações de uma empresa ou pessoa. Os fatos administrativos ou fatos contábeis, são os acontecimentos que afetam o patrimônio das entidades no aspecto quantitativo e qualitativo.

Desse modo, toda atividade com fins econômicos precisa ter sua organização financeira em dia. Assim, as informações geradas pela contabilidade são responsáveis pelo sucesso das empresas em crescimento independente do seu porte. 


\subsection{EMPRESAS RURAIS}

A empresa rural é definida como aquela que realiza atividades agrícolas com produção voltada ao mercado, visando à obtenção de lucros. É um empreendimento de pessoa física ou jurídica, pública ou privada, que explore econômica e racionalmente imóvel rural.

Marion (2014, p. 2) define que "empresas rurais são aquelas que exploram a capacidade produtiva do solo por meio do cultivo da terra, da criação de animais e da transformação de determinados produtos agrícolas". Ainda segundo Marion (2014, p. 2) as empresas rurais são divididas em três grupos:

- Agrícolas(cultivo da terra - produção vegetal)

- Zootécnicas (criação de animal - produção animal)

- Agroindustriais(transformação de produtos agropecuários).

Quanto as atividades agrícolas, as mesmas contemplam: cultura hortícola e forrageira: cereais, hortaliças, tubérculos, floricultura e, Arboricultura: pomares, florestamento.

- Atividade zootécnica: pecuária, avicultura, apicultura, ranicultura, cunicultura, piscicultura.

- Atividade agroindustrial: Produtos primários: beneficiamento primário de produtos agrícolas.

- Produtos agrícolas: transformação de produtos agrícolas.

- Produtos zootécnicos: transformação de produtos zootécnicos.

As empresas rurais são assim divididas e organizadas para um melhor entendimento das cadeias produtivas do agronegócio. Elas podem ser de pequeno, médio e grande porte, familiar ou não familiar. 


\subsection{PRODUTOR RURAL}

O produtor rural pessoa física é aquele que realiza atividade agrícola ou pecuária por meio do número de seu CPF com registro na receita federal. O PLS325/06 define que produtor rural é: "Pessoa física ou jurídica que explora a terra, com fins econômicos ou de subsistência, por meio da agricultura, da pecuária, da silvicultura, do extrativismo sustentável, da aquicultura, além de atividades não-agrícolas, respeitada a função social da terra".

O atual código civil considera empresário aquele que exerce de maneira profissional atividade econômica para produção de bens e serviços. Desse modo, o produtor rural é chamado de empresário rural, se inscrevendo na junta comercial, caso não se inscrever, ele será um produtor rural autônomo. (MARION, 2014, p. 7)

As pequenas e médias propriedades rurais são exploradas como pessoa física, pelo motivo de ser menos onerosa que a pessoa jurídica e ter mais vantagens de ordem fiscal, especialmente para as pequenas atividades. O pequeno e médio produtor rural como pessoa física não precisa fazer escrituração regular em livros contábeis.

Somente um livro-caixa e uma escrituração simplificada (MARION, 2014, p. 7).

Portanto, a forma de exploração da atividade rural como pessoa física ou jurídica, depende de uma avaliação cuidadosa, que deve levar em conta o tamanho e o custobenefício da atividade. Ao decidir por uma forma ou outra, o produtor precisa estar ciente das obrigações exigidas, de acordo com o tipo de exploração escolhida e atentar para a necessidade de fazer os devidos registros das atividades empregadas em seu negócio.

São obrigações acessórias da pessoa física:

- Declarações Anuais

- IRPF - Declaração de Ajuste Anual - Atividade Rural

- ITR - Imposto Territorial Rural 
- RAIS - Relação Anual de Informações Sociais

- Declarações Mensais

- GFIP - Guia de Recolhimento do Fundo de Garantia

- CAGED - Cadastro de Empregados e Desempregados

No caso das pequenas propriedades rurais, aquelas formadas por pequenos agricultores que produzem suas culturas com a mão de obra familiar é comum a falta de conhecimento de técnicas de gestão. Mas, por menor que seja o seu negócio ele precisa ser organizado. Pois, é de responsabilidade desses pequenos produtores boa parte dos alimentos que chegam à nossa mesa. Ainda que o pequeno produtor seja dispensado legalmente da escrituração contábil completa ele deve utilizar as ferramentas contábeis como apoio gerencial.

Entretanto, mesmo com o desenvolvimento do agronegócio e das novas tecnologias empregadas no meio rural, esse segmento ainda encontra desafios a serem superados. É comum em pequenas propriedades, o produtor ainda manter o antigo costume de guardar na memória as informações contábeis, e não as registrar, de forma obrigatória, ocasionando sérios prejuízos financeiros.

Mas, com a evolução da agricultura e o desenvolvimento do agronegócio, esse comportamento não cabe mais dentro dos empreendimentos rurais. O pequeno produtor precisa acompanhar o desenvolvimento tecnológico e fazer uso de novas tecnologias disponíveis no mercado.

\section{A IMPORTÂNCIA DA CONTABILIDADE}

\subsection{CONTABILIDADE COMO FERRAMENTA DE GESTÃO}

A contabilidade é um instrumento de organização. Não é necessidade exclusiva da pessoa jurídica, mas sim, também uma poderosa ferramenta de gestão para o pequeno produtor. Com o uso das ferramentas gerenciais é possível realizar 
procedimentos capazes de atender as necessidades de controle financeiro na propriedade.

Segundo Vilhena; Antunes (2010, p.4):

A conscientização do produtor rural, de que a contabilidade é uma ferramenta importante de gestão, que o planejamento e controle da produção são necessários em qualquer empreendimento, independentemente de seu porte, é uma tarefa árdua e difícil do profissional de contabilidade. Pois só assim, o contador cumprirá a sua função de gerar informações úteis para a tomada de decisão e consequente crescimento da empresa.

Desse modo, é fundamental ressaltar a importância da consultoria contábil para qualquer empreendimento. Pois, a legislação brasileira muda o tempo todo, e é preciso acompanhar as mudanças para não ficar para trás e nem deixar de cumprir as obrigações que lhe são devidas.

O sucesso de qualquer empreendimento depende de uma gestão organizada. Nesse sentido, é notável uma negligência por parte dos pequenos produtores, como já foi dito. Desse modo, a administração das pequenas empresas rurais precisa de mudanças urgentes em sua estrutura.

É a partir daí, que surge a importância da contabilidade no meio rural, pois, é uma área de conhecimento que oferece diferentes ferramentas contábeis para orientar o produtor nas decisões necessárias em sua atividade.

Oliveira (2012, p. 27) afirma que;

Assim, o produtor rural (pessoa física ou jurídica) utilizando as informações geradas pela contabilidade, tem condições de não somente controlar os custos e avaliar o resultado, mas principalmente, estabelecer planos e traçar estratégias que levem a propriedade rumo à eficiência na produção, mediante a observação das especificidades de cada tipo de cultura, do mercado e da tecnologia mais adequada para a atividade.

Partindo dessa premissa, surge a necessidade de controlar e gerenciar o patrimônio da empresa rural. Para isso, é preciso reconhecer e registrar os fatos administrativos 
que alteram o patrimônio. Com o conhecimento de técnicas e ferramentas da contabilidade é possível superar a carência existente na gestão da propriedade.

Segundo Athar (2005, p. 5):

Duas são as funções da contabilidade: a função econômica, que se expressa pela determinação do lucro, e a função administrativa, que representa em linhas gerais o controle do patrimônio. É por meio dos dados fornecidos pela contabilidade que o administrador tomará importantes decisões.

Quando aplicada corretamente e com o uso das demonstrações contábeis pertinentes, a contabilidade possibilita determinar o lucro e o controle do patrimônio, cumprindo assim, a suas funções econômica e administrativa. Para que essas funções sejam realizadas, é preciso fazer com cuidado o registro e controle de todas as operações econômicas e financeiras que acontece no negócio, como: compras, vendas, recebimentos e pagamentos.

\subsection{DEMONSTRAÇÃO DAS FERRAMENTAS GERENCIAIS}

As demonstrações contábeis são ferramentas de grande utilidade para o pequeno produtor, pois elas permitem a organização das atividades. São como fotografias do negócio, permitindo a visualização exata do desenvolvimento financeiro. Todas as demonstrações contábeis têm o objetivo de evidenciar a situação financeira do empreendimento, porém, cada uma tem sua particularidade e objetivos específicos. Desse modo, são instrumentos de gestão: o Inventário, o Livro Caixa, o Fluxo de caixa e Demonstração de Resultados do Exercício (DRE).

A microempresa e a empresa de pequeno porte, quando explora a atividade rural está dispensado da escrituração comercial na condição de manterem em bom estado e enquanto não decorrer o prazo decadencial. O livro-caixa, devendo estar escriturada toda a movimentação financeira e bancária. O livro de registro de inventário, devendo constar os estoques de cada ano calendário. $\mathrm{E}$ todos os documentos bases para escrituração dos livros - caixas e Registro de inventario.

(MARION, 2014, p.190).

RC: 82128

Disponível em:

https://www.nucleodoconhecimento.com.br/contabilidade/contabeiscomo-apoio 
Com tudo, é importante que o pequeno produtor rural gerencie seu negócio de maneira correta, através das ferramentas gerenciais apresentadas, que são de grande utilidade no dia a dia. Pois assim, como já foi dito antes, é possível visualizar o desenvolvimento do seu empreendimento. É evidentes e imediatas as vantagens que essas ferramentas podem fazer para uma organização.

\subsubsection{O INVENTARIO}

O inventário é um documento onde são listados detalhadamente todos os bens de uma pessoa ou entidade. Fazer uma gestão eficaz, pode ser um grande diferencial competitivo, para reduzir custos, otimizar as operações e garantir a rentabilidade do negócio. Diante disso, o Inventario em contabilidade é o ato de verificar o que existe na propriedade ou empresa. Como, mercadorias, produtos, materiais, bens imobilizados, contas a pagar ou a receber e outros bens que se façam necessários. (MARION, 2014, p.80).

Crepaldi (2016, p. 4) afirma que:

O empresário rural necessita conhecer exatamente a quantidade e o valor de cada bem que constitui o capital da empresa que dirige. É fácil verificar que os diversos tipos de capital apresentam características bem diferentes. Assim, as benfeitorias, os animais e as máquinas e implementos permanecem em uso na empresa durante vários anos. Já os insumos, uma vez utilizados, desaparecem imediatamente, sendo, portanto, consumidos dentro do ano agrícola em curso. Esse fato é de enorme importância para quem dirige uma empresa agrícola, porque o administrador deve ter especial cuidado com a conservação daqueles capitais que permanecem por vários anos na empresa.

Portanto, a utilização desse instrumento permite que o produtor ou proprietário tenha conhecimento de todo o seu patrimônio de forma detalhada. Tem como vantagem a organização e a identificação dos seus pertences. Sendo assim, é importante enfatizar que é por meio do inventário completo de uma propriedade rural que o empreendedor tem total controle sobre os recursos que envolvem o seu empreendimento. 
O inventario é de muita importância para o produtor, na fase de constituição ou organização da sua propriedade, é recomendável o método de inventario permanente e sempre fazer no final do ano ou exercício contábil. Para as atividades agrícolas esse método é mais vantajoso, pois, permite conhecer em todo momento o custo das culturas temporárias em formação.

O uso do inventário proporciona benefícios como:

- Relação completa dos bens presentes na propriedade.

- Conhecimento dos valores monetários de cada bem.

- $\quad$ Demonstra a quantidade de produtos e insumos em estoques. Figura 1.

Inventário geral

\begin{tabular}{|l|rr|rr||}
\hline \multicolumn{4}{|c|}{ Inventário geral em 05/01/2019 } \\
\hline \multicolumn{1}{|c|}{ Histórico } & \multicolumn{1}{|c|}{ Valor unitário } & \multicolumn{2}{c|}{ Valor total } \\
\hline Uma máquina benf. Café & & & $R S$ & $500.000,00$ \\
\hline $50 \mathrm{~s} /$ c de café árabica & $R S$ & 300,00 & $R S$ & $15.000,00$ \\
\hline Galpão com área de $400 \mathrm{~m} 2$ & & & $R S$ & $400.000,00$ \\
\hline $100 \mathrm{~s} / \mathrm{c}$ de adubo & $R S$ & 100,00 & $R S$ & $10.000,00$ \\
\hline $1.500 \mathrm{~kg}$ de cálcario & $R S$ & 4,00 & $R S$ & $6.000,00$ \\
\hline Um trator marca Massey fergunson & & & $R S$ & $100.000,00$ \\
\hline Área de terra cultivável 25.000m2 & & & $R S$ & $1.250 .000,00$ \\
\hline
\end{tabular}

Fonte: Elaborada pelos autores

\subsubsection{O LIVRO CAIXA}

O livro caixa é um documento utilizado nas atividades empresariais de todo porte, onde são registradas, todas as entradas e saídas de dinheiro e inclusive suas origens. São registrados ainda ,todos os pagamentos e as informações são organizadas de forma cronológica, dia mês e ano. Trata-se de um demonstrativo financeiro de fácil compreensão e utilização, onde são datadas e descritas as entradas e saídas que são realizadas dia a dia. 
Esse documento, além de ajudar a fazer os registros financeiros, contribui para a organização do estabelecimento. Através desta ferramenta é possível observar e controlar as atividades diárias. É uma forma de controle e que tem como vantagem auxiliar o produtor na hora de fazer o cálculo do imposto de renda.

É uma ferramenta simples e prática. Mas, precisa ser feito de forma diária e detalhada, o uso correto desta ferramenta traz vantagens e benefícios importantes, como:

- Acompanhar a movimentação financeira do empreendimento.

- Facilita a realização da declaração do imposto de renda.

- Demonstra fielmente a realidade da empresa.

Figura 2. Livro caixa

\begin{tabular}{|c|c|c|c|c|c|}
\hline \multicolumn{6}{|c|}{ Livro caixa } \\
\hline Data & Histórico & Entrada & Saída & & Saldo \\
\hline $04 / 01 / 2019$ & Saldo anterior & & & $R \$$ & $3.000,00$ \\
\hline $05 / 01 / 2019$ & Vendas à vista & $R \$ 3.000,00$ & & $R S$ & $6.000,00$ \\
\hline $06 / 01 / 2019$ & Recebimento de clientes & $R \$ 2.000,00$ & & $R \$$ & $8.000,00$ \\
\hline $07 / 01 / 2019$ & Pagamento de mão-de-obra & & $R \$ 1.000,00$ & $R \$$ & $7.000,00$ \\
\hline $08 / 01 / 2019$ & Compra de ferramentas & & $R \$ 500,00$ & $R \$$ & $6.500,00$ \\
\hline $09 / 01 / 2019$ & Compra de $10 \mathrm{~s} / \mathrm{c}$ de sementes & & $R \$ 1.500,00$ & $R \$$ & $5.000,00$ \\
\hline \multirow[t]{4}{*}{$10 / 01 / 2019$} & Despesas administrativas & & $R \$ \quad 250,00$ & $R \$$ & $4.750,00$ \\
\hline & & \multicolumn{2}{|c|}{ Saldo do mês } & $R S$ & $1.750,00$ \\
\hline & & \multicolumn{2}{|l|}{ Saldo anterior } & $R \$$ & $3.000,00$ \\
\hline & & \multicolumn{2}{|l|}{ Saldo atual } & $R \$$ & $4.750,00$ \\
\hline
\end{tabular}

Fonte: Elaborada pelos autores

\subsubsection{O FLUXO DE CAIXA}

O fluxo de caixa é uma ferramenta gerencial, onde são registradas todas as receitas e despesas. Por meio dela o gestor tem claramente o movimento do seu caixa, este demonstrativo evidencia as origens das entradas de recursos e também o destino das saídas desses recursos. Com tais informações o produtor tem segurança para decidir de forma mais assertiva. 
Deste modo, a utilização desta ferramenta possibilita o produtor analisar, por exemplo, se, há recursos suficientes para a organização, operar sem dificuldades ou se será preciso buscar outras fontes (recursos). É possível do mesmo modo, o produtor conhecer os custos e despesas de seu negócio, tendo assim mais segurança para calcular o seu preço de venda, prevenir problemas, solucioná-los a tempo e identificar alguma sobra de recursos para um possível investimento.

O fluxo de caixa tornou-se obrigatório no Brasil com a Lei no 11.638/87. Já obrigatória em outros países. No Brasil a adoção dessa norma possibilitou o avanço da contabilidade nacional e se adaptando as normas internacionais. (COSTA e NOGUEIRA, 2013, p. 30) Este registro permite a visualização da real situação da empresa, é também um demonstrativo de fácil compreensão e utilização, onde são descritas e datadas as entradas e saídas em um período determinado.

O uso desta ferramenta tem como benefícios básicos:

- Apresentar uma maior organização financeira.

- Antecipar decisões a partir de informações evidenciadas.

- Evita gastos desnecessários e possibilita fazer projeções.

Figura 3. Fluxo de caixa 


\begin{tabular}{|c|c|c|c|c|c|c|}
\hline \multicolumn{7}{|c|}{ Fluxo de caixa } \\
\hline \multirow{3}{*}{$\begin{array}{l}\text { Histórico } \\
\text { Entradas } \\
\text { Vendas }\end{array}$} & \multicolumn{6}{|c|}{ Período:Janeiro /2019 a Maio/2019 } \\
\hline & \multicolumn{2}{|c|}{ Janeiro } & Fevereiro & Março & Abril & Maio \\
\hline & $R S$ & $5.000,00$ & $R S$ S $6.000,00$ & $R S S \quad 7.000,00$ & RS $7.500,00$ & $R S \$ \quad 8.000,00$ \\
\hline Outros recebimentos & $R S$ & $4.000,00$ & $R S \$ \quad 4.500,00$ & $R \$ \quad 6.000,00$ & $R S \$$ & $R S \quad 5.500,00$ \\
\hline Contas à receber & $R S$ & $6.000,00$ & $R S \quad 5.000,00$ & $R \$ \quad 8.000,00$ & RȘ $\quad 6.000,00$ & $R S \quad 6.000,00$ \\
\hline Total de entradas & $R \hat{S}$ & $15.000,00$ & $R \$ 15.500,00$ & $R S \quad 21.000,00$ & $R S 19.000,00$ & $R \$ 19.500,00$ \\
\hline \multicolumn{7}{|l|}{ Saidas } \\
\hline Despesas administrativas & $R S$ & $1.500,00$ & $R S \hat{~} \quad 1.600,00$ & $R S \quad 1.600,00$ & $R S \quad 2.000,00$ & $R S \$ \quad 1.650,00$ \\
\hline Fomecedores & $R S$ & $2.000,00$ & $R S \$ \quad 2.000,00$ & $R S \quad 2.500,00$ & RS $1.600,00$ & $R S \$ \quad 2.000,00$ \\
\hline Salários à pagar & $R S$ & $2.000,00$ & $R S \quad 2.000,00$ & $R S \quad 2.000,00$ & $2.000,00$ & $R S \quad 2.000,00$ \\
\hline Total de saídas & $R S$ & $5.500,00$ & $R S \quad 5.600,00$ & $R S \quad 6.100,00$ & $R S \quad 5.600,00$ & $R S \quad 5.650,00$ \\
\hline Saldo=Entradas-Saídas & $R S$ & $9.500,00$ & $R S 9.900,00$ & $R S 14.900,00$ & $R S 13.400,00$ & $R \$ 13.850,00$ \\
\hline
\end{tabular}

Fonte: Elaborada pelos autores.

\subsubsection{DRE (DEMONSTRAÇÃO DO RESULTADO DO EXERCÍCIO)}

É um documento contábil elaborado em conjunto com o balanço patrimonial e tratase de uma ferramenta utilizada para analisar se o negócio em questão está sendo lucrativo ou está tendo prejuízo. O objetivo da DRE é apresentar a situação econômica de uma organização, é um relatório financeiro analisado de forma vertical onde as vendas brutas da empresa são apuradas com todas as deduções pertinentes. Receita bruta de vendas ou serviços menos (-) as deduções da receita bruta é igual (=) Receita liquida de vendas ou serviços menos (-) o custo de bens ou serviços vendidos é igual (=) O resultado bruto.

Desse modo, o benefício de se utilizar essa ferramenta é mostrar ao gestor o destino e a utilização dos recursos que estão sendo aplicados no empreendimento e assim considerar positiva ou negativa a rentabilidade do negócio.

Desse modo, observam-se algumas vantagens básicas desta demonstração:

- Fornecer ao gestor uma visão clara, sobre os gastos, despesas e lucro ou prejuízo. 
- Fornece informações importantes, que auxiliam a tomar decisões mais seguras.

- Com resultados positivos é possível atrair investidores e conseguir financiamentos.

Figura 4. Demonstração do Resultado do Exercício - DRE

\begin{tabular}{|l|rr||}
\hline \multicolumn{2}{|c|}{ Demonstração do Resultado do Exercicio (DRE) } & \multicolumn{3}{c|}{ 06/2018 a 06/2019 } \\
\hline Receita Operacional Bruta & $R \$$ & $600.000,00$ \\
\hline (-)Imposto Sobre Vendas & $R S$ & $40.000,00$ \\
\hline (-) Devolução de Vendas & $R S$ & $2.000,00$ \\
\hline (=) Receita Operacional liquida & $R \$$ & $562.000,00$ \\
\hline (-) Custo das Mercadorias Vendidas & $R S$ & $150.000,00$ \\
\hline (=) Resultado Operacional Bruto & $R \$$ & $412.000,00$ \\
\hline (-) Despesas com Juros & $R \$$ & $2.000,00$ \\
\hline (-) Despesas com Manutenção & $R S$ & $1.000,00$ \\
\hline (=) Resultado Operacional & $R \$$ & $411.000,00$ \\
\hline
\end{tabular}

Fonte: Elaborada pelos autores.

Como já foi explanado anteriormente, as ferramentas apresentadas são básicas, fáceis e de grande utilidade para o pequeno produtor, independente da forma de exploração do negócio, física ou jurídica, a organização é a chave do sucesso. Com a falta desses registros e controles da produção, o produtor ignora o lucro gerado pela venda dos seus produtos causando o desconhecimento da renda anual gerada pela empresa.

Tendo em mãos a ferramenta certa, o gestor otimiza o seu tempo e conta com benefícios relevantes ao tomar suas decisões. Assim, terão uma visão dos gastos e podem visualizar onde os recursos estão sendo aplicados. De posse, e conhecimento de informações importantes, o produtor é capaz de gerenciar tranquilamente o seu negócio. Mas, sempre considerar a vantagem de se consultar um profissional habilitado no caso um contador para orientações mais precisas e relevantes. 


\section{CONCLUSÃO}

Com a necessidade de conscientizar os pequenos produtores para a importância de organizar seu empreendimento no sentido financeiro e, superar o desafio de registrar diariamente os atos e fatos administrativos que afetam o seu patrimônio, pretendeuse, evidenciar esse desafio no meio rural e sinalizou algumas possíveis soluções.

Através das demonstrações foi possível chamar a atenção dos pequenos produtores e conscientizá-los da necessidade e importância de uma organização administrativa, valorizando a contabilidade e visualizando a propriedade como uma empresa. Para isso, foi apresentado os conceitos de contabilidade rural e, sua importância nas pequenas propriedades. Foi apresentado como ferramentas gerenciais; o inventario, o livro caixa, o fluxo de caixa e a DRE com seus, conceitos, finalidade e principalmente os benefícios de sua utilização, facilitando assim, um melhor entendimento do assunto abordado.

Esse estudo tem uma importância fundamental para os pequenos produtores rurais e todos os envolvidos no segmento do agronegócio. A pesquisa possibilitou uma análise e aprofundamento dos conhecimentos exigidos. O tema de grande abrangência garantiu uma vasta bibliografia consultada e, desse modo, os objetivos pretendidos foram alcançados. Foi possível demonstrar para o pequeno produtor a importância da contabilidade e apresentar de forma prática as ferramentas gerenciais que podem ser utilizadas em sua empresa rural.

\section{REFERÊNCIAS}

AUGUSTO, J. A. P. Origem, evolução e objetivos da contabilidade, 2009.

CALLADO, A. A. C; CALLADO, A. L. C. Custos na tomada de decisões em empresas rurais 2017.

CARNEIRO, Juvenal \& Eryma; Tratado de Contabilidade Rural 1933. 
COSTA, José Manoel da; NOGUEIRA, Daniel Ramos; Analise das demonstrações contábeis 2013.

CHERMAN, Bernardo C. Contabilidade geral. Rio de Janeiro: Freitas Bastos, 2005.

GOMES, Aguinaldo Rocha. Contabilidade rural \& agricultura familiar.

Rondonópolis: A. R. Gomes, 2002.

HORNGRE, C.T; SUNDEM, G. L; STRATTON, W. O. Contabilidade Gerencial. 12. ed. São Paulo: Prentice Hall, 2004.

MARION, José Carlos. Contabilidade rural. 1. ed. São Paulo: Atlas, 1985.

MARION, J. C. Contabilidade rural. 14. ed. São Paulo: Atlas, 2014.

, J. C. Contabilidade empresarial. 16. ed. São Paulo: Atlas, 2012.

SENAR, Finanças Aplicadas ao Agronegócio. Brasília: 2016

SENAR, Contabilidade Rural. Brasília: 2015 SEBRAE.

Disponível em: www.sebrae.com.br Enviado:

Fevereiro de 2021.

Aprovado: Abril de 2021. 